\title{
Ethanol as a stimulus to risky and auto-aggressive behaviour
}

\author{
Dorota Lasota $^{1, A-F} \oplus$, Witold Pawłowski ${ }^{2, C-F}{ }^{\oplus}$, Dagmara Mirowska-Guzel ${ }^{1, D-F} \oplus$, \\ Krzysztof Goniewicz ${ }^{3, D-F} \oplus$, Mariusz Goniewicz ${ }^{2, D-F} \oplus$ \\ ${ }^{1}$ Medical University, Warsaw, Poland \\ ${ }^{2}$ Medical University, Lublin, Poland \\ ${ }^{3}$ Military University of Aviation, Dęblin, Poland \\ A - Research concept and design, B - Collection and/or assembly of data, C - Data analysis and interpretation, \\ $D$ - Writing the article, $E$ - Critical revision of the article, $F$ - Final approval of article
}

Lasota D, Pawłowski W, Mirowska-Guzel D, Goniewicz K, Goniewicz M. Ethanol as a Stimulus to Risky and Auto-Aggressive Behaviour. Ann Agric Environ Med. 2021; 28(2): 220-223. doi: 10.26444/aaem/118861

\begin{abstract}
According to the World Health Organization (WHO), ethyl alcohol occupies the third place among health risks for the general population, causing damage to health as well as social damage. Ethanol is also considered the greatest risk factor in injuries. Both alcohol and its main metabolite, acetaldehyde, are directly toxic to tissues and lead to several systemic pathologies. Alcohol abuse may also lead to mental health disorders. Although one-in-eight adult Poles abstains from drinking alkohol, $10-20 \%$ of adult Poles drink alcohol regularly. It is estimated that this group includes about 900,000 addicts, and over $2,000,000$ people who drink alcohol at a risky or harmful level. It affects their occurrence and their consequences Drinkdriving is one of the problems most often raised, although alcohol is a documented risk factor in pedestrian accidents. It is also an important risk factor for suicidal behaviour with people under the influence of alcohol choosing more radical and effective methods of committing suicide, such as hanging or 'throwing themselves under a moving vehicle.' Only properly selected and consistently taken preventive actions can improve the tragic statistics related to ethanol stimulating risky and auto-aggressive behaviours. It is also necessary to improve the system for reporting such events because only reliable statistics enable proper assessment of the scale of the problem, and the effectiveness of these activities.
\end{abstract}

\section{Key words}

alcohol, ethanol, injuries, traffic accidents, suicides

\section{INTRODUCTION}

According to the World Health Organisation (WHO), alcohol is the third most important risk factor for harm to the health of the population. Only smoking and hypertension pose a higher risk. Both alcohol and its main metabolite, acetaldehyde, are directly toxic to tissues and lead to several systemic pathologies. Alcohol abuse may also lead to mental health disorders. Although one-in-eight adult Poles abstains from drinking alcohol, $10-20 \%$ of adult Poles drink alcohol regularly. It is estimated that this group includes about 900,000 addicts and over 2,000,000 people who drink alcohol at a risky (drinking to excess without any negative consequences at present) or harmful level (drinking causing damage to health, physical or mental, but also psychological and social, without addiction). Ethanol is one of the most commonly used psychoactive substances causing risky and auto-aggressive behaviour.

The basic pathomechanism of ethanol is its depressive effect on the central nervous system (CNS) and the modulating effect on CNS neurotransmitter systems is of greatest significance. Ethanol enhances the activity of gamma-aminobutyric acid (GABA), i.e. the main neurotransmitter that inhibits neuronal function in the CNS, which results in an influx of chloride ions to neurons. At the same time, it inhibits NMDA receptors (ionotropic receptors with the ability to bind a synthetic compound similar in structure to glutamate

Address for correspondence: Dorota Lasota, Medical University of Warsaw, Poland E-mail: dorota.lasota@wum.edu.pl

Received: 10.02.2020; accepted: 09.03.2020; first published: 20.03.2020 and N-methyl-D-aspartic acid aspartate), which makes it difficult for calcium ions to penetrate them. In addition to its effects on the nervous system, ethanol also induces several metabolic disorders, such as hypoglycaemia, ketoacidosis, and electrolyte disorders (hypokalaemia, hypocalcaemia, hypomagnesaemia, hypophosphataemia). Depending on the concentration in the blood, alcohol produces a specific effect, although the relationship is not strict:

$<0.25 \mathrm{~g} / \mathrm{l}(\%)^{*}-$ good mood;

0.25-0,5 g/l - euphoria, reduced criticism;

0.5-1 g/l - impaired coordination of movements, awkwardness, reduced reaction time;

1-2.5 g/1 - ataxia, speech impairment, nystagmus;

$>2.5 \mathrm{~g} / 1 \quad-$ possible coma;

$>4.0 \mathrm{~g} / \mathrm{l} \quad-$ loss of deep reflexes (risk of choking), respiratory problems, possible death [1].

The aim of this review is an assessment of recent literature devoted to the impact of ethanol on behaviour relevant to public health, including risky and auto-aggressive behaviour.

\section{METHODS}

The review comprised a search on electronic databases for articles containing the key words "alcohol", "ethanol", "injuries", "traffic accidents" and "suicides". Reviews were included where authors explicitly addressed and made

\footnotetext{
${ }^{\star} \mathrm{X}(\mathrm{g} / \mathrm{L})=\mathrm{X}(\% \mathrm{o})$
} 
recommendations for ethanol, utilizing experience and good practice in the conduct and reporting of systematic reviews. After a preliminary analysis of the abstracts of the articles that met the search criteria, all those not directly related to the topic of the thesis were rejected. Selected full texts, based on the abstract analysis, were then analyzed. Finally, only the literature relevant to the review were analyzed.

Injuries occurring under the influence of alcohol. Ethanol is considered to be the most important risk factor for injuries. It is estimated to be responsible for the death of approximately $30 \%$ of injured patients. After consumption, ethanol increases the risk of all types of injuries caused by traffic accidents, self-inflicted injuries, etc. $[2,3,4,5]$.

Studies by Lasota et al. on the impact of ethanol on the severity of injuries in fatal road traffic accidents involving pedestrian victims, demonstrated that the effect of ethanol on injury severity cannot be mentioned without taking into account the gender and age of the victims $[6,7]$.

Many studies have also assessed the relationship between alcohol and fatal and non-fatal injuries. The results are in favour of a better prognosis and lower mortality rates among people with isolated head injuries [8-13] sustained after the consumption of ethanol, compared to sober people, although the severity of such injuries tended to be higher. However, this „neuroprotective“effect of ethanol is observed only in single doses of ethanol, which This is can be explained by the inhibition of glutamatergic NMDA receptor activity in the CNS $[14,15]$. Like most NMDA receptor antagonists, ethanol consumed chronically is a neurotoxin $[14,15,16,17]$.

In multiorgan injuries, the negative influence of ethanol on the course of treatment has been observed mainly due to an increase in the number of complications which, however, does not translate directly into an increase in mortality [18-25]. In ethanol users who suffered multiple organ injuries, there are often numerous complications in the form of multiple organ failure, severe pneumonia or delayed wound healing. When considering the causes of complications of alcohol intoxication, the adverse effects have been indicated of ethanol on the cardiovascular system (decreased arterial pressure, disruption of compensatory mechanisms after haemorrhaging and vomiting caused by its ingestion), may result in aspiration pneumonia and various immunological disorders [26]. It has been proven that ethanol inhibits the activity of monocytes and macrophages, inhibits the synthesis of TNFa (tumour necrosis factor) and interleukin 8 (IL-8), thus demonstrating immunosuppressive effects [27]. Thist increases the risk of post-traumatic infections, Acute Respiratory Distress Syndrome (ARDS) and Multiple Organ Dysfunction Syndrome (MODS).

Risky behaviour under the influence of ethanol. Most drinkers imbibe alcohol in a way that does not cause either a negative impact on visible damage to health or entail social consequences. However, there are some people who should not drink at all, e.g. road users. A significant percentage of traffic accidents occur in people under the influence of ethanol, e.g. in Poland in 1997, there occurred the biggest number of accidents caused by people under the influence of alcohol (18.6\% of all accidents). Since 1997, the situation has improved [28], although the percentage of accidents involving intoxicated individuals in Poland remains at an average level, compared to data from other EU countries [29].
Studies on the role of ethanol in road traffic accidents indicate that ethanol is a factor that has a significant influence on their occurrence and effects. The problem of drink-driving is the most commonly discussed, although alcohol is a documented risk factor also for pedestrian accidents, and intoxicated pedestrians pose a potential risk to themselves and other road users [30,31, 32, 33]. Even low concentrations of ethanol cause visual-motor coordination disorders, speech impairment, delayed reaction times, problems with balance and self-control of one's behaviour. Higher concentrations, more than $4 \%$ o (when 1 promil $=100 \mathrm{mg}$ of alcohol $/ 1$ decilitre of blood) can be fatal. According to the WHO, the risk of accidents for drivers increases starting from $0.05 \mathrm{~g} / \mathrm{dl}$; at a level of $0.1 \mathrm{~g} / \mathrm{dl}$, the risk is already 5 times higher [34]. There is no "safe" concentration of ethanol in the blood in terms of its influence on the impairment of concentration and efficiency. The road traffic risk of drunk persons represents a mathematical evaluation of the risk of an accident occurring (road accident risk indicator) when a driver is found to be intoxicated. At a blood alcohol concentration of $0.3 \%$ o the risk is 7 times greater, between $1-1.49 \%$ o the risk is 31 times greater, and over 1.5\%o - 120 times greater. Several studies have led to the conclusion that at blood alcohol concentration levels above $1.0 \%$, drivers should be declared unfit to drive $[35,36,37]$. In Poland, the permissible level of ethanol in the blood of a driver is $0.2 \%$. Road Traffic Law forbids anyone from driving a vehicle while intoxicated, under the influence of alcohol or any similarly acting substance [38]. When the blood alcohol content is at or nears a concentration of $0.2 \%$ - $0.5 \%$ o (or presence of $0.1 \mathrm{mg}-0.25 \mathrm{mg}$ of alcohol/1 $\mathrm{dm} 3$ in exhaled air), this is considered to be a state after alcohol consumption [37]. When the blood alcohol level is at or nears a blood alcohol level above $0.5 \%$ (i.e. more than $0.25 \mathrm{mg} / 1 \mathrm{dm} 3$ in exhaled air), this is the state of intoxication $[39,40]$. Driving a motor vehicle while intoxicated or under the influence of an intoxicant is a criminal offence [40]; however, the notions of intoxication and alcohol consumption in Polish criminal law do not refer to the concentration of $0.1 \% 0(0.10 \mathrm{~g} / \mathrm{l})$, which may be explained by the fact that ethanol in low concentrations and quantities is formed endogenously in the human body as a result of metabolic processes $(<0.01 \mathrm{~g} / \mathrm{l}$, according to some to $0.15 \mathrm{~g} / \mathrm{l}$ ) [1]. Thus, the sobriety threshold is $0.19 \%$ o and the value of $0.2 \%$ is an offence. At this point, it should be noted that the "intoxication" of pedestrians does not give rise to legal liability, although it also poses a serious threat to road safety [30, 31, 32, 33].

Ethanol effects on auto-aggression behaviour. Of all the psychoactive substances, alcohol is the strongest predictor of impulsive and auto-aggressive behaviour [41]. According to the WHO, of all deaths from suicide, $22 \%$ can be attributed to the use of alcohol, which means that one in every 5 suicides in the population could be avoided if alcohol had not been consumed [42]. It is estimated that between $34 \%-56 \%$ of suicide bombers abuse or are addicted to alcohol, and the risk of suicide bombers in this group is between $2 \%-3.4 \%$, which is 6 times higher than in people who are not burdened with this diagnosis $[43,44,45,46]$. The simultaneous occurrence of affective disorders increases the level of impulsivity and auto-aggression [47].

However, regardless of the nature of alcohol use disorder (AUD), it is an important risk factor for suicidal behaviorus. On the population level, the influence of ethanol 
(consumption, abuse, addiction) on the occurrence of suicide has been confirmed by a positive correlation between the amount of alcohol consumed and suicide rates [48]. It is worth noting that in Poland in 2017, more people died from suicide than in road accidents - 5,276 vs. 2,831 [49].

People under the influence of alcohol also choose more radical and consequently more effective methods of committing suicide $[50,51]$. According to the WHO, suicides are most often committed through deliberate consumption of pesticides, which applies mainly to rural areas and agricultural regions of the world. In highly developed countries, $50 \%$ of suicides are through hanging and $18 \%$ by firearms [52].

In Poland, hanging is the most common method of committing suicide [53]. According to the Polish Police database in $2017,4,313$ (81.75\%) (out of 5,276 fatal suicides were performed by hanging. At the time of death, 341 (6.46\%) people were sober, $602(11.41 \%)$ were under the influence of ethanol, $13(0.25 \%)$ under the influence of psychotropic substances, 729 (13.82\%) under the influence of other substances, and in 4,276 (81.05\%) cases, the state of consciousness was not established (several categories can refer to one instance of suicide) [49].

There many studies indicating the occurrence of the socalled seasonality of behaviours of suicide (,temperature in spring", Morselle) [54]. They show that the peak of suicides can be observed in the spring months, although some analyses indicate that the peak can also be observed in autumn [55]. The seasonality phenomenon also applies to suicide attempts [56]. Research conducted by Lasota et al. also confirmed the existence of the phenomenon of the seasonality of suicides among victims of suicides under the influence of alcohol. They showed that the model of seasonal variability of suicides depends on the gender of the victims [57].

Another radical, although much less frequently chosen method, is „staged“suicide traffic accidents. A report by the Finnish Transport Safety Agency (TRAFI) for 2008-2013 shows that 169 people in Finland took their lives on the roads during that period, $84 \%$ of whom were drivers of vehicles and $16 \%$ were pedestrians, and that more than one-third of all of them were under the influence of alcohol at the time of the accident [58]. Unfortunately, in Poland, „road traffic suicides"are often classified as road traffic accidents caused, e.g. by the fact that the speed was not adjusted to the road conditions, or by veering off the road for unexplained reasons into the oncoming traffic lane. Such events are not recorded in the suicide statistics.

Another method is "trespassing onto railway tracks." This is a method that guarantees a certain and swift death, as well as being easily accessible and non-life-threatening for third parties. The factors that guarantee this efficiency are the long braking distance of a trains, their very large mass, the inability to change tracks when an obstacle is encountered, the speed at which the train moves, and injuries to the whole body, which result in poor chances of survival and a quick death [59]. In such cases, it is necessary to initiate proceedings to explain the cause of the event, i.e. whether it was an accident (usually the result of crossing the railway tracks at an unauthorized place), suicide on railway tracks, or perhaps even homicide. To this end, special investigative bodies have been set up under the Railway Safety Directive [60]. In Poland, this is the National Commission for Railway Accident Investigation. The change in the classification of the direct cause of a railway accident into suicide is made only based on a judgment by the Public Prosecutor's Office. Suicides and suicide attempts constitute a separate group in the statistics and are not included in the classification of railway accidents. Official statistics on suicides in Poland currently come from two databases, i.e. the National Police Information System (KSIP10) and the Central Statistical Office (GUS), based on death certificates, which unfortunately results in serious discrepancies in the reported data $[49,60]$. Moreover, the above-mentioned events are described in these statistics as "throwing oneself under a moving vehicle“, which seems to be too much of a generalization and does not specify the actual method of committing suicide.

\section{CONCLUSIONS}

Alcohol is the strongest factor predisposing to risky and selfdestructive behaviours that lead to accidents and result in severe injuries or death. In order to effectively prevent such incidents, such as common road traffic accidents, or suicide attempts or attacks? and in order to limit their number and consequences, it is necessary to undertake appropriately selected and consistently implemented preventive actions in the form of, e.g. health campaigns and programmes, as well as technical solutions to improve safety (barriers separating traffic lanes, closed stations, fences preventing unauthorized access to railway lines, etc.). It is also necessary to improve the system of reporting such events because only reliable statistics enable the proper assessment of the scale of the problem and the effectiveness of these activities.

\section{REFERENCES}

1. Trias-Llimós S, Kunst AE, Jasilionis D, Janssen F. The contribution of alcohol to the East-West life expectancy gap in Europe from 1990 onward. Inter J Epidemiol. 2018; 47(3): 731-739.

2. Fortuna LR, Porche MV, Padilla A. A treatment development study of cognitive and mindfulness-based therapy for adolescents with cooccurring post-traumatic stress and substance use disorder. Psychology and Psychotherapy: Theory, Research and Practice. 2018; 91(1): 42-62.

3. Auerbach RP, et al. Mental disorders among college students in the World Health Organization world mental health surveys. Psychol Med. 2016; 46(14): 2955-2970.

4. Marx W, Moseley G, Berk M, Jacka F. Nutritional psychiatry: the present state of the evidence. Proceedings of the Nutrition Society. 2017; 76(4): 427-436.

5. Bell RL, et al. A genetic animal model of alcoholism for screening medications to treat addiction. Int Rev Neurobiol. 2016; 126: 179-261. Academic Press.

6. Lasota D, et al. The effect of ethyl alcohol on the severity of injuries in fatal pedestrian victims of traffic crashes. PLoS One. 2019; 14(9).

7. Lasota D, et al. Effects of ethyl alcohol on injuries severity according to injury severity scales in pedestrian fatal injury in traffic crashes. Int J Inj Contr Saf Promot. 2019; 1-9.

8. Gjerde H, Romeo G, Mørland J. Challenges and common weaknesses in case-control studies on drug use and road traffic injury based on drug testing of biological samples. Ann Epidemiol. 2018; 28(11): 812-820.

9. Watling CN, Armstrong KA, Smith SS, Wilson A. The on-road experiences and awareness of sleepiness in a sample of Australian highway drivers: A roadside driver sleepiness study. Traffic Inj Prev. 2016; 17(1): 24-30.

10. Burns E, Kakara R. Deaths from falls among persons aged $\geq 65$ yearsUnited States, 2007-2016. MMWR Morb Mortal Wkly Rep. 2018; 67(18): 509.

11. Esser MB, et al. Characteristics associated with alcohol consumption among emergency department patients presenting with road traffic injuries in Hyderabad, India. Inj. 2016; 47(1): 160-165. 
12. Koh DH, et al. Cancer incidence and mortality among temporary maintenance workers in a refinery/petrochemical complex in Korea. Int J Occup Environ Health. 2014; 20(2): 141-145.

13. Geulayov $\mathrm{G}$, et al. Incidence of suicide, hospital-presenting nonfatal self-harm, and community-occurring non-fatal self-harm in adolescents in England (the iceberg model of self-harm): a retrospective study. The Lancet Psychiatry. 2018; 5(2): 167-174.

14. Wang J, et al. Postsynaptic RIM1 modulates synaptic function by facilitating membrane delivery of recycling NMDARs in hippocampal neurons. Nat Commun. 2018; 9(1): 1-15.

15. Newman EL, et al. A role for prefrontal cortical NMDA receptors in murine alcohol-heightened aggression. Neuropsychopharmacology. 2018; 43(6): 1224-1234.

16. Chastain LG, Sarkar DK. Role of microglia in regulation of ethanol neurotoxic action. Int Rev Neurobiol. 2014; 118: 81-103). Academic Press.

17. Gaddini GW, et al. Alcohol: a simple nutrient with complex actions on bone in the adult skeleton. Alcohol Clin Exp Res. 2016; 40(4): 657-671.

18. Pereira RB, Andrade PB, Valentao P. A comprehensive view of the neurotoxicity mechanisms of cocaine and ethanol. Neurotoxicity Res. 2015; 28(3): 253-267.

19. Natarajan SK, Pachunka JM, Mott JL. Role of microRNAs in alcoholinduced multi-organ injury. Biomolecules. 2015; 5(4): 3309-3338.

20. Li CY, et al. Metabolomic study on idiosyncratic liver injury induced by different extracts of Polygonum multiflorum in rats integrated with pattern recognition and enriched pathways analysis. Front Pharmacol. 2016; 7: 483.

21. González-Reimers E, et al. Effects of Alcohol on the Corpus Callosum. In: Neuroscience of Alcohol. Academic Press. 2019; 143-152.

22. Li Y, et.al. Autophagy in alcohol-induced multiorgan injury: mechanisms and potential therapeutic targets. BioMed research international. 2014.

23. Gyongyosi B, et al. Alcohol-induced IL-17A production in Paneth cells amplifies endoplasmic reticulum stress, apoptosis, and inflammasomeIL-18 activation in the proximal small intestine in mice. Mucosal Immunol. 2019; 12(4): 930-944.

24. French SW. Chronic alcohol binging injures the liver and other organs by reducing NAD+ levels required for sirtuin's deacetylase activity. Exp Mol Pathol. 2016; 100(2): 303-306.

25. Cabarcos P, et al. Quantification of fatty acid ethyl esters (FAEE) and ethyl glucuronide (EtG) in meconium for detection of alcohol abuse during pregnancy: correlation study between both biomarkers. J Pharmaceutical Biomedical Analysis. 2014; 100: 74-78.

26. Wang Q, et al. The clinical phenotypes of autoimmune hepatitis: a comprehensive review. J autoimmun. 2016; 66: 98-107.

27. Saha B, Momen-Heravi F, Kodys K, Szabo G. MicroRNA cargo of extracellular vesicles from alcohol-exposed monocytes signals naive monocytes to differentiate into M2 macrophages. J Biolo Chem. 2016; 291(1): 149-159.

28. Nowak M, Papiernik M, Mikulska A, Czarkowska-Paczek B. Smoking, alcohol consumption, and illicit substances use among adolescents in Poland. Subst Abuse Treat Prev Policy. 2018; 13(1): 42.

29. Mierzecki A, Kłoda K, Guźmińsk B, Morżak-Bożedajek A, Chełstowski K. Alcohol Drinking Pattern Is Associated with Demographic Features of Primary Health Care Patients in Poland: A Cross-Sectional Study. Med Sci Monit: Int Med J Exp Clin Res. 2018; 24: 2083.

30. Papalimperi AH, Athanaselis SA, Mina AD, Papoutsis II, Spiliopoulou CA, Papadodima SA. Incidence of fatalities of road traffic accidents associated with alcohol consumption and the use of psychoactive drugs: A 7-year survey (2011-2017). Exp Ther Med. 2019; 18(3): 2299-2306.

31. Haghpanahan $\mathrm{H}$, et al. An evaluation of the effects of lowering blood alcohol concentration limits for drivers on the rates of road traffic accidents and alcohol consumption: a natural experiment. The Lancet. 2019; 393(10169): 321-329.

32. Blais E, Maurice P. Toward improved evaluations of laws against drinkdriving. The Lancet. 2019; 393(10169): 297-298.

33. Valen A, Bogstrand ST, Vindenes V, Frost J, Larsson M, Holtan A, Gjerde $H$. Driver-related risk factors of fatal road traffic crashes associated with alcohol or drug impairment. Accid Anal Prev. 2019; 131: 191-199.

34. World Health Organization. Global status report on alcohol and health 2018. World Health Organization 2019.

35. Asgarian FS, Namdari M, Soori H. Worldwide prevalence of alcohol in fatally injured motorcyclists: A meta-analysis. Traffic Inj Prev. 2019; 20(7): 685-689.

36. Rolison JJ, Regev S, Moutari S, Feeney A. What are the factors that contribute to road accidents? An assessment of law enforcement views, ordinary drivers' opinions, and road accident records. Accid Anal Prev. 2018; 115: 11-24.

37. Jørgenrud B, Bogstrand ST, Furuhaugen H, Jamt RE, Vindenes V, Gjerde $\mathrm{H}$. Association between speeding and use of alcohol and medicinal and illegal drugs and involvement in road traffic crashes among motor vehicle drivers. Traffic Inj Prev. 2018; 19(8): 779-785.

38. Pawłowski W, et al. The effect of ethyl alcohol upon pedestrian trauma sustained in traffic crashes. Int J Environ Res Public Health. 2019; 16(8): 1471.

39. Timmins MA, et al. Does state dissociation mediate the relation between alcohol intoxication and deliberate self-harm? Arch Suicide Res. 2019; 1-12.

40. Evans JR, et al. The impact of alcohol intoxication on witness suggestibility immediately and after a delay. Appl Cogn Psychol. 2019; 33(3): 358-369.

41. O'Brien J. States of Intoxication: The Place of Alcohol in Civilisation. Routledge 2018

42. Johnson EG, Skromanis S, Bruno R, Mond J, Honan CA. Inhibiting automatic negative social responses in alcohol intoxication: interactions with theory of mind ability and level of task guidance. Psychopharmacol. 2018; 235(4): 1221-1232.

43. Rehm J, et al. Alcohol dependence and very high risk level of alcohol consumption: a life-threatening and debilitating disease. Addict Biol. 2018; 23(4): 961-968.

44. Baykova MA, Merinov AV. Influence of parental alcoholism on suicidal and personality-psychological characteristics of offspring. IP Pavlov Russian Med Biol Herald. 2018; 26(4): 547-558.

45. Bartoli F, et al. Testing the association of serum uric acid levels with behavioral and clinical characteristics in subjects with major affective disorders: A cross-sectional study. Psychiatry Res. 2018; 269: 118-123.

46. Keane S, Szigeti A, Fanning F, Clarke M. Are patterns of violence and aggression at presentation in patients with first-episode psychosis temporally stable? A comparison of 2 cohorts. Early Interv Psychiatry. 2019; 13(4): 888-894.

47. Balabanova V, et al. Nonsuicidal self-injury in mentally ill patients: a clinical case. Neurology, Neuropsychiatry, Psychosomatics. 2019; 11(3): 83-88.

48. Smith MM, et al. The perniciousness of perfectionism: A meta-analytic review of the perfectionism-suicide relationship. J Personality. 2018; 86(3): 522-542.

49. General Police Headquarters of Poland: Zamachy samobójcze od 2017 (Suicide attempts since 2017). Available online: http://www.statystyka. policja.pl/st/wybrane-statystyki/zamachy-samobojcze/63803/ [retrieved: 21.11.2018]. (in Polish)

50. Caetano R, et al. Precipitating circumstances of suicide and alcohol intoxication among US ethnic groups. Alcoholism: Clin Exp Res. 2015; 39(8): 1510-1517.

51. Yuodelis-Flores C, Ries RK. Addiction and suicide: a review. Am J Addict. 2015; 24(2): 98-104.

52. Park $\mathrm{CH}$, et al. Impact of acute alcohol consumption on lethality of suicide methods. Compr Psychiatry. 2017; 75: 27-34.

53. Lasota D, et al. Alcohol intoxication and suicide by hanging in Poland. Alcohol Alcohol. 2020. https://doi.org/10.1093/alcalc/agaa013

54. Orellana J, Souza C, Souza M. Hidden suicides of the indigenous people of the Brazilian Amazon: gender, alcohol and familial clustering. Revista colombiana de psiquiatria. 2019; 48(3): 133-139.

55. Bagge $\mathrm{C}$, et al. Alcohol use to facilitate a suicide attempt: an event-based examination. J Stud Alcohol Drugs. 2015; 76(3): 474-481.

56. Lasota D, et al. Seasonality of suicides among victims who are under the influence of alcohol. Int J Environ Res Public Health. 2019; 16(15): 2806.

57. Niskanen L, Partonen T, Auvinen A, Haukka J. Excess mortality in Finnish diabetic subjects due to alcohol, accidents and suicide: a nationwide study. Eur J Endocrinol. 2018; 179(5): 299-306.

58. Darnell D, Dunn, C, Atkins D, Ingraham L, Zatzick DA randomized evaluation of motivational interviewing training for mandated implementation of alcohol screening and brief intervention in trauma centers. J Subst Abuse Treat. 2016; 60: 36-44.

59. Nowacki G, Olejnik K, Zakrzewsk, B. Safety Status on Road Transport System in the European Union. In International Conference on Reliability and Statistics in Transportation and Communication. 2018; 457-467. Springer, Cham.

60. Central Statistical Office of Poland. Available online: https://stat.gov. pl/ [retrieved: 01.10.2019]. (in Polish) 